\section{Education, regulation, representation and remuneration in dentistry - who does what?}

\author{
S. Tabiat-Pour, ${ }^{1}$ T. Pepper ${ }^{2}$ and N. L. Fisher ${ }^{3}$ \\ VERIFIABLE CPD PAPER
}

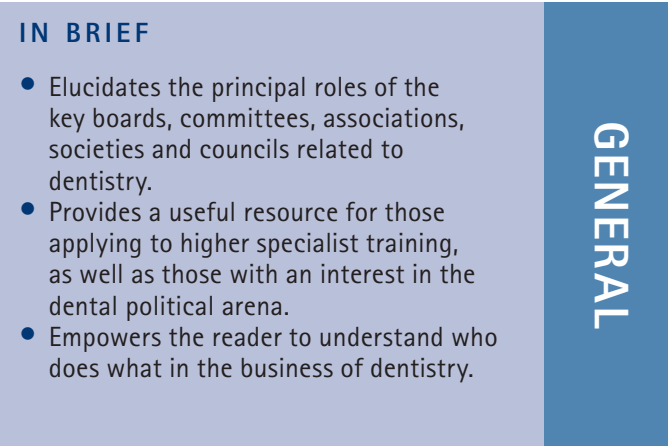

\begin{abstract}
Dentistry in the United Kingdom demands a wide range of supportive and regulative bodies, the roles of which are intertwined, overlapping and changeable. The interaction between these bodies is not always clear, and often the present-day role of the body is far removed from its original purpose. Consequently, the system can appear daunting and opaque. Even so, a thorough understanding of this topic is requisite for those considering applying for higher specialist training, and pertinent for practitioners with an interest in the dental political arena. We hope this paper goes some way towards unravelling the tangle of boards, committees, associations, societies and councils that commonly influence dentistry, and provides a starting point for those interested in increasing their knowledge of the profession at the strategic level.
\end{abstract}

\section{INTRODUCTION}

In the current politicofinancial climate, all public sector organisations - in particular the NHS - are experiencing a period of unprecedented change. ${ }^{1}$ Within this turbulent and evolving environment is the organisational machinery engaged with the day-to-day education, regulation, representation and remuneration of dentists in the UK. However, the interaction between these bodies is not always clear, and often the contemporary role of the body is disparate from the purpose for which it was originally conceived. Despite these difficulties, a thorough understanding of this topic is requisite for those considering applying for higher specialist training and pertinent for practitioners with an interest in the dental political arena.

This paper aims to outline the principal roles of the key boards, committees, associations, societies and councils related to dentistry, as well as the interplay between them, in order to confer a broad understanding of this somewhat nebulous

\footnotetext{
${ }^{1 *}$ Specialist Registrar in Restorative Dentistry, Guy's Dental Hospital, ${ }^{2}$ Consultant in Restorative Dentistry, Guy's \& St. Thomas' Hospital NHS Foundation Trust, Guy's Hospital, Great Maze Pond, London, SE1 9RT; ${ }^{3}$ Medical student, King's College London, Guy's Campus, London, SE1 1UL

Correspondence to: Ms Sara Tabiat-Pour

Email: saratpour@hotmail.com
}

\section{Refereed Paper}

Accepted 9 December 2010

DOI: $10.1038 /$ sj.bdj.2011.340

${ }^{\circledR}$ British Dental Journal 2011; 210: 431-438 landscape. In the interests of simplicity, not all detail has been given for each country of the UK, but wherever possible we have outlined the distinguishing factors.

\section{DEPARTMENT OF HEALTH (DH)}

The Department of Health is the UK government department with overall responsibility for health and social care in England. The devolved governments of the United Kingdom each have their own health departments, namely the Department of Health and Social Services (Welsh Assembly Government), the Health Directorates (The Scottish Government), and the Department of Health, Social Services and Public Safety (Northern Ireland Executive). While every department is responsible for elements of its own health policy and service, the DH deals with non-devolved matters and issues common to all systems.

The DH does not deliver care services directly but develops policy according to decisions taken in Parliament. The Secretary of State for Health, a Cabinet appointment, is responsible for the DH and accountable to Parliament. He or she is appointed by the Crown after nomination by the Prime Minister. The Department is led by the various Health Ministers*,

*Minister of State for Health, Minister of State for Care Services, Parliamentary Under-Secretary of State for Quality (Lords), and the Parliamentary Under-Secretary of State for Public Health each of whom has areas of responsibility related to their appointment (for instance, the Parliamentary Under-Secretary of State for Public Health is responsible for public health measures such as fluoridation, while the Parliamentary Under-Secretary of State for Quality is responsible for dentistry, among other things). The DH's Permanent Secretary is a civil servant who does not play a political role, does not change with governments, and is responsible for the overall efficient running of the DH. The majority of healthcare in England is delivered by NHS bodies, and this close link between the NHS and the DH is reflected in the fact that the NHS Chief Executive - the government's principal adviser on all NHS issues - also works for the DH.

There are six chief professional officers working for the Department of Health, of which the Chief Dental Officer (CDO) is one (the others being Chief Medical, Nursing, Health Professions, Pharmaceutical and Scientific Officers). The CDO is the professional head of dental staff and provides the government with expert knowledge on all matters relating to dentistry in England, as well as providing leadership and disseminating policy to the profession through letters and CDO Update. Separate CDOs work for the devolved governments in Scotland, Wales, and Northern Ireland.

A series of 25 National Clinical Directors (also known as tsars) work for the DH. They 
essentially spearhead change, each overseeing the implementation of a National Service Framework ${ }^{\ddagger}$ or strategy for key health issues (such as cancer or diabetes), or key patient groups (for example, children). In this role they also work with the Royal Colleges to ensure that changes in health and social services are reflected in training and education.

The future role of the Department of Health is proposed to feature a radical reduction in NHS functions, thereby allowing greater focus on improving public health. ${ }^{1}$

\section{NATIONAL HEALTH SERVICE (NHS)}

The NHS began operating in July 1948 with the ambition that 'Everybody, irrespective of means, age, sex or occupation shall have equal opportunity to benefit from the best and most up-to-date medical and allied services available... services should be comprehensive and free of charge....' However, within a few years the cost of providing a fully comprehensive service had soared beyond the Government's most pessimistic predictions. In an attempt to mitigate its effect, patient charges were implemented for dentistry, prescriptions, and spectacles.

Today the NHS is the world's largest publicly-funded healthcare service. Although funded centrally from national taxation, the devolved administrations manage their NHS services separately. ${ }^{3}$ Strictly speaking, the health service in England solely carries the title 'NHS', with the other UK services designated 'NHS Wales', 'NHS Scotland', and 'Health and Social Care in Northern Ireland' (HSC). However, the systems are similar in many respects and, subtle differences (for example, prescription fees) aside, they are generally referred to as a single, unified system. Indeed, a resident in one country of the UK can freely seek treatment in another country of the UK.

In 2002, the government created Strategic Health Authorities in England. These are controlled by the DH and manage the regional NHS on behalf of the Secretary of State for Health. There were originally 28 SHAs, but in 2006 this number was reduced. The current NHS hierarchy in

\footnotetext{
${ }^{\dagger}$ A systematic approach to improving quality across healthcare sectors through defined national standards, service models, and performance measures
}

England consists of ten regional ${ }^{\S}$ Strategic Health Authorities (SHAs), which hold their local NHS Trusts - Primary Care Trusts, Acute Trusts, Ambulance Trusts, Care Trusts and Mental Health Trusts - to account for their performance. SHAs are directly accountable to the DH and NHS Chief Executive, and are responsible for developing plans to improve health services in their area as well as ensuring that DH directives and policy are integrated into local health service plans.

At the time of writing, approximately $80 \%$ of the $£ 100$ billion NHS budget is directly allocated by the DH to primary care trusts (PCTs). PCTs are responsible for assessing the needs of their local population and ensuring that there is a comprehensive array of primary care and public health services available (for example, dentistry, pharmacy and optician services). PCTs also play a large role in commissioning secondary care. In 2006 their number was reduced from 303 to 152 with the aim of combining services and reducing costs. Six of these PCTs are Care Trusts - agreements between the NHS and local authorities resulting in a close relationship between health and social care. While the services that PCTs deliver are all NHS-funded, they may be provided by private companies (for example, Independent Sector Treatment Centres). A health White Paper ${ }^{1}$ proposes to phase out PCTs and SHAs by 2013, moving responsibility for commissioning the majority of health services to consortia of GP practices (who will likely buy in support from other organisations, such as local authorities, voluntary organisations and the independent sector ${ }^{4}$ ). Primary care dentistry (and other family services such as community pharmacy and primary ophthalmic services) is likely to be outwith this, most probably being the responsibility of a newly created independent NHS Commissioning Board derived from the current NHS Management Board of the DH.

Acute Trusts manage hospitals and employ the clinical and non-clinical workforce therein. Foundation Trusts are those Acute Trusts that have demonstrated financial judiciousness and as a result have been granted greater fiscal and operational autonomy. They are

${ }^{s}$ North East, North West, Yorkshire and the Humber, West Midlands, East Midlands, South West, South Central, East of England, London, and South East Coast independent from SHA and DH control and represent one element of the government's decentralisation of public services. Approximately two thirds of hospitals have currently achieved Foundation Trust status; the g overnment's aim is for all NHS Trusts to become Foundation Trusts by 2013. Foundation Trusts are regulated by Monitor," a body that reports directly to Parliament and that has been proposed to become a full economic regulator for the NHS. ${ }^{1}$

\section{NATIONAL INSTITUTE FOR HEALTH AND CLINICAL EXCELLENCE (NICE)}

The National Institute for Clinical Excellence was established in $1999^{5}$ with the aim of promoting clinical excellence in England and Wales and establishing parity across regions with regard to the range of treatments available, thereby abolishing the so-called postcode lottery that was apparent at the time. In 2005 NICE merged with the Health Development Agency ${ }^{6}$ to become the National Institute for Health and Clinical Excellence - a special health authority (SpHA, an Arm's Length Body - see Table 1) of the NHS in England only. Its future role will include developing quality standards for adult social care. ${ }^{7}$

NICE publishes guidance in three areas: health technologies (for example, ozone treatment), clinical practice (for example, dental recall intervals), and public health (for example, smoking cessation services). The decisions it makes with regard to its guidance are intended to be apolitical, being based entirely on clinical efficacy and costeffectiveness. NICE's public health guidance is applicable solely to England; the remainder of its guidance is applied in varying amounts to Wales, Northern Ireland, and Scotland, dependent on government agreement. Since 2002 in England, and 2003 in Wales, the NHS has been legally obligated to fund medicines and treatments within three months of recommendation by NICE's technology appraisal board. ${ }^{8}$

Three organisations in Scotland provide analogous functions to NICE in England. NHS Quality Improvement Scotland (NHS QIS) processes NICE technology appraisals and discerns their validity for NHS Scotland. The Scottish Intercollegiate Guidance Network (SIGN) was formed

\footnotetext{
"An Arm's Length Body - see Table 1
} 


\begin{tabular}{|c|c|c|c|}
\hline Arm's Length Body subtype & Special Health Authority & Non-Departmental Public Body & Executive Agency \\
\hline Definition & $\begin{array}{l}\text { An independent body, but subject to ministerial } \\
\text { direction like other NHS bodies. SpHAs provide } \\
\text { a service to the public and/or the NHS, and } \\
\text { generally provide a service for the whole } \\
\text { population of England, rather than for a } \\
\text { particular local community }\end{array}$ & $\begin{array}{l}\text { A body which has a role in the } \\
\text { processes of national government, but } \\
\text { is not a government department or } \\
\text { part of one. }{ }^{9} \text { Also known as a 'quango' }\end{array}$ & $\begin{array}{l}\text { A body which is still part of, and } \\
\text { accountable to, the DH but responsible } \\
\text { for a particular business area and } \\
\text { managerially and budgetarily separate }\end{array}$ \\
\hline Examples & NICE, NHSBSA & CQC, Monitor, DDRB & MHRA \\
\hline
\end{tabular}

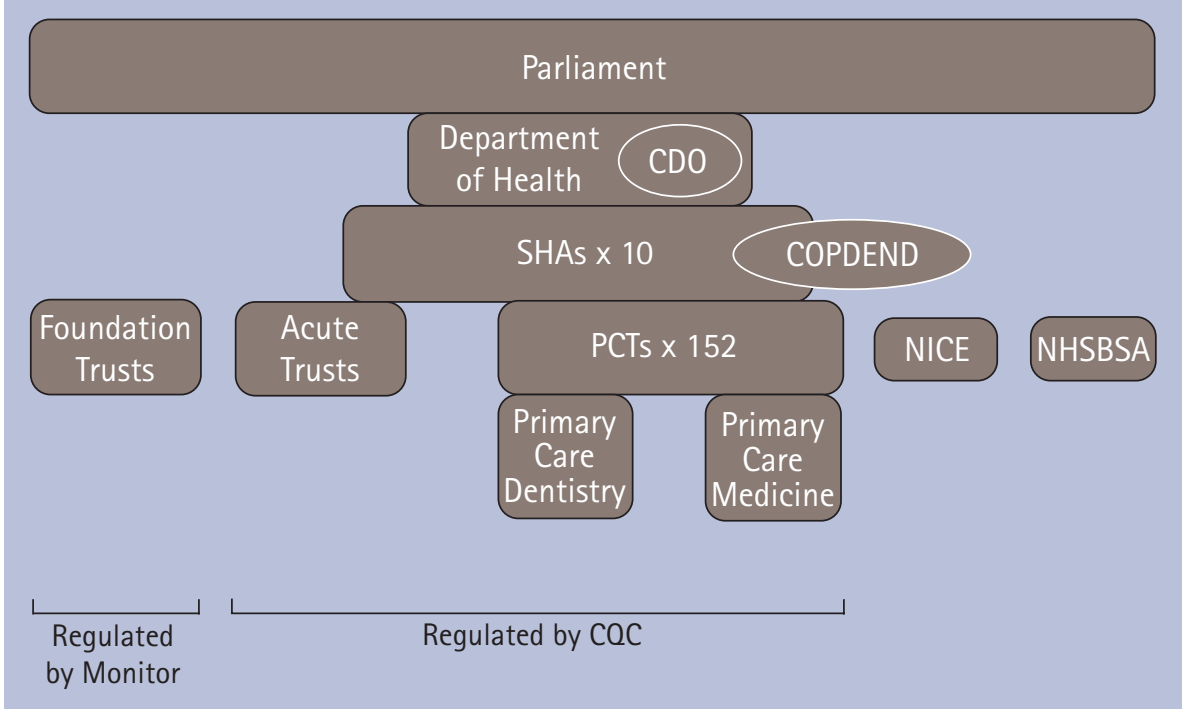

Fig. 1 Simplified schematic of current NHS organisation structure with relevance to dentistry

in 1993 and develops clinical practice guidelines; in 2005 it was subsumed into NHS QIS. Lastly, the Scottish Medicines Consortium (SMC) issues advice to NHS Scotland on the suitability of all newly licensed medicines for NHS use within 12 weeks of product availability.

\section{NHS BUSINESS SERVICES AUTHORITY (NHSBSA)}

The NHS Business Services Authority is another special health authority. It replaced the Dental Practice Board (as well as several other authorities and agencies) in $2006 .{ }^{10}$ Among other wide-ranging functions - from managing the NHS pension scheme to administrating the European Health Insurance Card (EHIC) - it provides payment to dentists for work undertaken on an NHS contract and produces statistics relating to NHS dentistry. By processing NHS dental transactions at a national level with other NHS transactions it is able to take advantage of economies of scale.

Within the NHSBSA, the Dental Reference Service (DRS) exists to provide quality assurance for clinical dentistry in the General and Personal Dental Services. PCTs or Local Health Boards may request the DRS to interview and examine patients, as well as review clinical records and inspect practices. In the near future the NHSBSA will undergo commercial review in order to identify potential opportunities for greater private sector involvement. ${ }^{7}$

\section{CARE QUALITY COMMISSION (COC)}

In 2009, another Arm's Length Body, the Care Quality Commission, replaced the Healthcare Commission, Mental Health Act Commission, and the Commission for Social Care Inspection. ${ }^{11}$ The CQC now regulates all health and social care services in England (both public and independent sectors; see Figure 1) with the aim of ensuring consistent standards of quality across the services. The CQC is concerned with the 'provider' of these services (which may be an individual, partnership, or organisation running, for instance, a hospital, nursing home, ambulance service, or voluntary organisation) rather than individual clinicians, who are registered with their own regulatory bodies.

Reports from the CQC are intended to be patient-centric and are released into the public domain. If providers do not meet

TThe Welsh equivalent of an SHA essential quality standards they face a variety of measures including public warnings, fines, suspension, or deregistration. Since April 2010, NHS Trusts have been required to register with the $\mathrm{CQC}$ in order to operate legally. Private and NHS dental practices must be registered with the CQC by April 2011. It is proposed that in the future, the CQC will operate a joint licensing regime with Monitor, as well as acting as host organization for HealthWatch England, which will be established as an independent patient champion. ${ }^{7}$

\section{GENERAL DENTAL COUNCIL (GDC)}

The General Dental Council is dentistry's regulatory body in the UK - it is one of 13 health and social care regulators." The GDC itself is overseen by the Council for Healthcare Regulatory Excellence (CHRE), which also oversees the other eight health profession regulatory bodies.

The GDC evolved in 1956 from its predecessor, the Dental Board of the General Medical Council, after the 1956 Dentists Act acknowledged that the dental profession had earned the right to self-government. The GDC's prime purpose is the protection of patients and the public interest through the maintenance of a register of qualified dentists and, latterly, dental care professionals (DCPs). Only individuals listed on the registers are legally permitted to carry out the practice of dentistry. ${ }^{12}$

Originally, non-lay members of the GDC were dentists elected by the registrants. Following the Shipman Inquiry ${ }^{13}$ and proposals in a subsequent government White Paper, ${ }^{14}$ in 2009 the Council became a fully appointed body ${ }^{15,16}$ and currently consists of 12 lay members, eight dentists, and four

"The others being the General Medical, Optical, Pharmaceutical, Chiropractic, Osteopathic, and Social Care Councils, the Nursing and Midwifery Council, Health Professions Council, Pharmaceutical Society of Northern Ireland, Scottish Social Services Council, Care Council for Wales, and the Northern Ireland Social Care Council 
DCPs. ${ }^{17}$ The Council sets standards for professional conduct, and indirectly controls the undergraduate curriculum by setting the learning outcomes of dental undergraduates. ${ }^{18}$ The Council also provides quality assurance $^{* *}$ for undergraduate dental education, inspecting all UK dental schools every six years. Courses are checked annually in the interim by means of a 'monitoring form' in which the course provider must detail progress made with respect to the recommendations and requirements outlined in the GDC's inspection report. ${ }^{19}$ The GDC also deals with complaints, administers the Overseas Registration Exam, makes decisions regarding registrants' fitness to practise, and from $2014^{20}$ will determine the suitability of dentists for revalidation. These wide-ranging functions are carried out by a variety of dedicated committees, boards, and working groups within the GDC.

As well as maintaining the register of dentists and DCPs, the GDC maintains the specialist lists. ${ }^{21}$ As far back as 1991 the GDC indicated its intention to identify individual dental specialties, with the aim of protecting patients from unwarranted claims of specialist expertise. ${ }^{22}$ A subsequent report by the $\mathrm{CDO}^{23}$ supported the introduction of specialist lists and also took into account the recommendations of the Calman Report $^{24}$ that were shaping postgraduate medical training. The report confirmed the GDC as having 'overall supervisory responsibility for courses of training leading to formal qualifications as a practitioner of specialised dentistry with ultimate responsibility for the award of a Certificate of Completion of Specialist Training (CCST)'. However, an arrangement ${ }^{25-27}$ was reached whereby the Royal Colleges, specialist societies, universities, and postgraduate Dental Deans would continue to develop curricula, examinations, and training programmes for the specialties. In 1998, nine specialist lists were opened by the GDC, and these have since grown to encompass 13 GDCrecognised specialties (Table 2). The GDC are currently considering opening new specialist lists in Implant Dentistry and Maxillofacial Orthodontics. ${ }^{28}$

The establishment of the CQC alongside the GDC has resulted in concerns ${ }^{29}$

\footnotetext{
**The policies, standards, systems and processes directed to ensuring maintenance and enhancement of quality ${ }^{31}$
}

\begin{tabular}{|c|c|c|c|}
\hline 1998 & 1999 & 2000 & 2008 \\
\hline Oral surgery (3) & Oral medicine (5) & Oral pathologya (4) & Special care dentistry (3) \\
\hline Restorative dentistry (5) & & Oral microbiology (5) & \\
\hline Dental public health (4) & & $\begin{array}{l}\text { Dental and maxillofacial } \\
\text { radiology (4) }\end{array}$ & \\
\hline \multicolumn{4}{|l|}{ Surgical dentistry ${ }^{b}$} \\
\hline \multicolumn{4}{|l|}{ Endodontics (3) } \\
\hline \multicolumn{4}{|l|}{ Periodontics (3) } \\
\hline \multicolumn{4}{|l|}{ Prosthodontics (3) } \\
\hline \multicolumn{4}{|l|}{ Paediatric dentistry (3) } \\
\hline Orthodontics (3) & & & \\
\hline
\end{tabular}

regarding duplication and over-burdensome regulation. Consequently, an agreement ${ }^{30}$ has been reached which coordinates how the respective organisations will discharge their roles and responsibilities. The Memorandum states that the GDC has the lead role in relation to concerns about individuals' fitness to practise, performance and conduct, with the CQC taking the lead in relation to concerns about providers' compliance with regulations. Additionally, both organizations will ensure that there is no duplication of enforcement by agreeing that only one organization will act at a time where appropriate. ${ }^{30}$

\section{COMMITTEE OF POSTGRADUATE DENTAL DEANS AND DIRECTORS (COPDEND)}

England is divided into eleven geographic regions ${ }^{\ddagger \ddagger}$ (not in all cases coincident with the SHA boundaries), each with a Postgraduate Dental Dean or Director (plus one Defence Dean for the UK). COPDEND is the committee of these Dental Deans and Directors, who are integrated within the structure and functions of SHAs in England. ${ }^{26}$ Lead Deans are appointed to represent the deaneries where necessary (for instance, in liaison with the NHS, DH, or Royal Colleges); each Lead Dean represents a specialty or specialties and acts both as a conduit for information and a focal point for advice.

While the GDC provides quality assurance for undergraduate and specialist

\footnotetext{
*tondon, KSS, East of England, Oxford, South Yorkshire/East Midlands, West Midlands, Yorkshire, South West, Mersey, North West, Northern
}

training, and SHAs are responsible for supporting workforce planning and the commissioning of postgraduate medical and dental education (PGMDE), the remit of postgraduate Dental Deans extends to cover delivery of all NHS-related postgraduate education and training, including the provision of CPD. Since 2006, when the Dental Vocational Training Authority ceased to exist, postgraduate dental deaneries have also taken on responsibility for providing quality assurance for Dental Foundation training and advising PCTs on assessing equivalence to VT.

In addition to these responsibilities, the deaneries play a role in workforce planning (that is, the recruitment and retention of dentists and DCPs), ensuring adequate training opportunities are available to meet the future needs of the NHS, and maintaining a database of dentists in specialty training through the allocation of National Training Numbers. In keeping with this, Deans have responsibility for the appointment of trainees, training programme directors, and VT trainers, as well as for the conduct of Record of In-Training Assessments (RITAs) and Annual Reviews of Competence Progression (ARCPs), quality management ${ }^{\S \S}$ of specialty training programmes, ${ }^{32}$ and the recommendation of Certificates of Completion of Specialist Training (CCST) to the GDC.

${ }^{\S \S}$ The arrangements by which the postgraduate deanery satisfies itself that local education and training providers are meeting the agreed standards through robust reporting and monitoring mechanisms ${ }^{38}$ 
Each deanery has a number of Specialist Training Committees (STCs), the Chairs of which are appointed by the regional postgraduate dean. STCs representing the deanery may seek the advice of the relevant SAC on any matter relating to specialist training. STCs meet several times per year to discuss all aspects of their respective specialty training programmes, advise the Deanery on training numbers and manpower issues, and address any difficulties that have arisen within training schemes.

\section{DENTAL SCHOOLS COUNCIL (DSC)}

The Dental Schools Council (formerly the Council of Heads and Deans of Dental Schools) is the representative body of the UK's 16 dental schools. The Dean (or equivalent) of each dental school sits on the Council and attends meetings approximately three times per year to discuss matters pertaining to dental education and research. While the GDC set the learning outcomes, ${ }^{18}$ dental schools are responsible for developing curricula and assessment methodologies that effectively deliver these outcomes.

\section{ROYAL COLLEGE OF SURGEONS (RCS)}

The Royal Colleges of Surgeons of England, Edinburgh, Glasgow, and Ireland are charities dedicated to promoting excellence in all surgical fields, including dental surgery. The Royal Colleges provide educational courses and examinations in the surgical specialties, and have specialty input into NICE guidance as well as producing their own clinical guidelines. In addition, they act as an advisory body to the DH, SHAs, Trusts, and GDC.

There are two dental faculties within the Royal College of Surgeons of England - the Faculty of Dental Surgery (FDS), and the Faculty of General Dental Practice (FGDP), each headed by a Dean. The FDS supports specialists and dentists working in secondary care in England, while the FGDP is dedicated to primary care dentists and dental care professionals UK-wide. ${ }^{33}$ Examination for the Diploma of Membership of the FDS (MFDS) was originally a prerequisite for entry into specialist training, while the Diploma of Membership of the FGDP (MFGDP) was the first step in the career pathway for dentists in general practice.
In 2005, the GDC abolished the need for candidates to hold MFDS or equivalent to enter specialist training, ${ }^{34}$ and in 2007 the Diploma of Membership of the Joint Dental Faculties (MJDF) effectively replaced both MFDS and MFGDP ${ }^{35}$ in England.

Within the FDS are eight ${ }^{\prime \prime \prime I}$ intercollegiate Specialist Advisory Committees (SACs) which advise on training in the dental specialties. In addition, the SACs keep a national register of trainees. Each SAC has a core group composed of: ${ }^{36}$

- $4 \times$ Faculty representatives (one from each Faculty)

- $1 \times$ Postgraduate Dental Dean

- $4 \times$ Members of specialist societies

- $1 \times$ Trainee representative.

Each individual SAC has additional membership to suit its particular circumstances. One of the main roles of an SAC is to develop curricula for the dental specialties, which are then subject to GDC approval.

FDS maintains a network of Regional Advisers who represent it at a local level, covering broadly similar areas to the Postgraduate Deaneries. Several Specialty Advisers are also appointed to each region, and they provide specialty-specific advice to the Regional Adviser. Smaller specialties are catered for by National Advisers. The regional Specialty Adviser often doubles as the Chair of the Deanery's Specialty Training Committee. This joint appointment ensures close liaison between the higher training programme, the Deanery, and the Royal College.

In 2010, RCS England established Specialist Advisory Panels (SAPs) in order to provide the FDS with expert advice for nine ${ }^{\text {If }}$ of the dental specialties. SAPs' responsibilities include advising on specialty membership examinations, advising on the need for courses in the UK and abroad in their relevant specialty, assisting in the selection of examiners, and considering development of courses for specialist $\mathrm{CPD} /$ revalidation. Additionally, the SAP will recommend a representative in their

IIIIOral and maxillofacial surgery, oral surgery, restorative dentistry, paediatric dentistry, orthodontics, dental public health, special care dentistry, and additional dental specialties

"Oral and maxillofacial surgery, oral surgery, restorative dentistry, paediatric dentistry, orthodontics, dental public health, special care dentistry, oral and maxillofacial pathology, and oral medicine

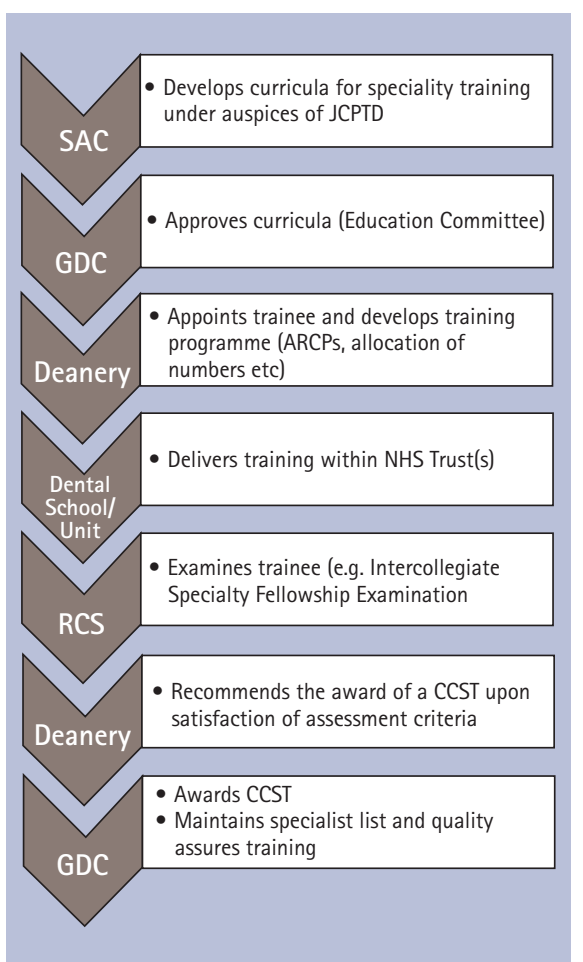

Fig. 2 Specialty training workflow under regulation of the Gold Guide

specialty area for nomination to the SAC by the Dean. Figure 2 outlines the current specialty training workflow.

RCS England offers four journals of relevance to dentistry. The Annals of the $R C S$ contains peer-reviewed papers pertaining to all branches of surgery, while the quarterly Faculty Dental Journal (published by FDS) conveys expert opinion on a wide range of issues. Finally, Team In Practice and Primary Dental Care from FGDP(UK) are dedicated to teamworking and research in primary care dentistry respectively.

The Royal Colleges of Edinburgh, Glasgow, and Ireland have corresponding dental faculties and offer analogous examinations to those discussed so far. Notably, the RCS of Edinburgh is home to the Royal Odonto-Chirurgical Society of Scotland, which was founded in 1867 and which is the oldest dental society in the UK. ${ }^{37}$

\section{JOINT COMMITTEE FOR POSTGRADUATE TRAINING IN DENTISTRY (JCPTD)}

In June 2010 the JCPTD replaced the JCSTD (Joint Committee for Specialist

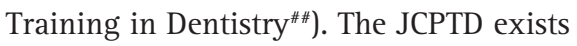

\footnotetext{
\#\#ormerly the Joint Committee for Higher Training in Dentistry
} 
to facilitate an integrated continuum of dental education with particular emphasis on foundation and specialist training, and with provision for revalidation as required by the GDC. ${ }^{38}$ In this regard, internal to the JCPTD are the Advisory Boards for Dental Foundation Training and Specialty Training in Dentistry (ABDFT and ABSTD, respectively). The stakeholders represented on the JCPTD are many and varied (Fig. 3). The Committee meets at least twice a year at one of the Royal Colleges.

Under the JCSTD, SACs were periodically required to inspect specialty training programmes. However, since 2008 Deaneries have taken over responsibility for the quality management of training programmes according to GDC requirements. ${ }^{26}$

\section{REPRESENTATIVE BODIES}

The British Dental Association is the largest representative body for dental practitioners in the UK. ${ }^{39}$ Founded in 1880 from the Dental Reform Committee, its original role was concerned with prosecuting the many illegal practitioners not registered under the Dentists Act 1878. However, with the 1921 Dentists Act came the Dental Board of the GMC which now fulfilled this role, freeing the BDA for other purposes.

The contemporary remit of the BDA is multifaceted, involving trade union, scientific, professional, and service roles. The Association promotes the views and concerns of the profession at a local and national level; it also provides guidance for practice management matters, advice sheets for use by clinical staff, as well as a twice-monthly journal. The BDA library houses the most comprehensive collection of dental literature in Europe, and its museum holds the largest collection of dental artefacts in Britain.

The BDA is also the main advocate for dentistry with regard to evidence submitted to the Review Body on Doctors' and Dentists' Remuneration (DDRB), an Arm's Length Body (Table 1). The DDRB is a nondepartmental public body which invites evidence from a variety of stakeholders and then provides an independent recommendation to the government on how much doctors' and dentists' pay should increase in the following year. Notably, the government has instructed the DDRB not to make recommendations for the 2011/12 and 2012/13 financial years; it intends to
Table 3 Acronym buster

\begin{tabular}{|c|c|}
\hline ABDFT & Advisory Board for Dental Foundation Training \\
\hline ABSTD & Advisory Board for Specialty Training in Dentistry \\
\hline ALB & Arm's Length Body \\
\hline ARCP & Annual Review of Competence Progression \\
\hline BDA & British Dental Association \\
\hline CCST & Certificate of Completion of Specialist Training \\
\hline CDO & Chief Dental Officer \\
\hline CHRE & Council for Healthcare Regulatory Excellence \\
\hline COPDEND & COmmittee of Postgraduate DENtal Deans and directors \\
\hline CPD & Continuing Professional Development \\
\hline $\mathrm{COC}$ & Care Quality Commission \\
\hline DCP & Dental Care Professional \\
\hline DDRB & Review Body on Doctors' and Dentists' Remuneration ('Doctors' and Dentists' Review Body') \\
\hline $\mathrm{DH}$ & Department of Health \\
\hline DRS & Dental Reference Service \\
\hline DSC & Dental Schools Council \\
\hline FDS & Faculty of Dental Surgery \\
\hline FGDP & Faculty of General Dental Practice \\
\hline GDC & General Dental Council \\
\hline GMC & General Medical Council \\
\hline HSC & Health and Social Care in Northern Ireland \\
\hline ISTC & Independent Sector Treatment Centre \\
\hline JCPTD & Joint Committee for Postgraduate Training in Dentistry \\
\hline MFDS & Member of the Faculty of Dental Surgery \\
\hline MFGDP & Member of the Faculty of General Dental Practice \\
\hline MHRA & Medicines and Healthcare products Regulatory Agency \\
\hline MJDF & Member of the Joint Dental Faculties \\
\hline NCD & National Clinical Director ('Tsar') \\
\hline NDPB & Non-departmental Public Body \\
\hline NHS OIS & National Health Service Quality Improvement Scotland \\
\hline NHSBSA & National Health Service Business Service Authority \\
\hline NICE & National Institute for health and Clinical Excellence \\
\hline NSF & National Service Framework \\
\hline NTN & National Training Number \\
\hline ORE & Overseas Registration Examination \\
\hline PCT & Primary Care Trust \\
\hline PGMDE & Post-Graduate Medical and Dental Education \\
\hline QUANGO & Quasi-Autonomous Non-Governmental Organization \\
\hline RCS & Royal College of Surgeons \\
\hline RITA & Record of In-Training Assessment \\
\hline SAC & Specialist Advisory Committee \\
\hline SAP & Specialist Advisory Panel \\
\hline SHA & Strategic Health Authority \\
\hline SIGN & Scottish Intercollegiate Guidance Network \\
\hline SMC & Scottish Medicines Consortium \\
\hline SpHA & Special Health Authority \\
\hline STC & Specialty Training Committee \\
\hline VT & Vocational Training \\
\hline
\end{tabular}




\begin{tabular}{|c|c|}
\hline Body & Summary of role with relevance to dentistry \\
\hline $\mathrm{DH}$ & Creates policy and disseminates to the dental profession \\
\hline NHS & Delivers services to patients \\
\hline NICE & $\begin{array}{l}\text { Appraises technology, clinical practice, and public health measures in order to ensure } \\
\text { that, if efficacious and cost-effective, they are available throughout the NHS }\end{array}$ \\
\hline NHSBSA & $\begin{array}{l}\text { Provides payment to dentists for NHS work. Numerous other functions not directly } \\
\text { related to dentistry }\end{array}$ \\
\hline $\mathrm{COC}$ & $\begin{array}{l}\text { Regulates (public and independent) health and social care services in England (but } \\
\text { note that NHS Foundation Trusts are regulated by Monitor). Undertakes and pub- } \\
\text { lishes the results of providers' performance on the quality of services }\end{array}$ \\
\hline GDC & $\begin{array}{l}\text { Maintains registers of dentists, specialists, and DCPs. Approves curricula for } \\
\text { undergraduate and specialty training. Provides quality assurance for undergradu- } \\
\text { ate and specialty training programmes. Awards CCSTs. Administers ORE. Carries out } \\
\text { disciplinary proceedings }\end{array}$ \\
\hline Dental Deaneries & $\begin{array}{l}\text { Appoint STC Chairs, training programme directors, DF1 advisers and trainers, and } \\
\text { trainees to posts. Deliver/commission postgraduate dental training (both general } \\
\text { and specialty) at a local level. Conduct RITAs/ARCPs. Recommend award of CCSTs to } \\
\text { GDC. Quality manage the delivery of postgraduate specialty training programmes } \\
\text { to GDC standards. Quality assure Dental Foundation training and advise PCTs on } \\
\text { equivalence to VT. Input into the development of dental workforce strategy }\end{array}$ \\
\hline Dental Schools & Develop curricula for the award of degrees and diplomas \\
\hline $\mathrm{RCS}$ & $\begin{array}{l}\text { Advisory to the DH, SHAs, Trusts, and GDC. Administers postgraduate examinations. } \\
\text { Through the SACs and JCPTD, develops curricula and assessments for specialty } \\
\text { training (subject to GDC approval). Produces and approves clinical guidelines. } \\
\text { Provides advice on the award of CCSTs to clinical academics }\end{array}$ \\
\hline $\begin{array}{l}\text { BDA/specialist } \\
\text { associations }\end{array}$ & $\begin{array}{l}\text { Represent the profession during dealings with the government and employing } \\
\text { authorities. Promote the interests of the profession. Provide expert advice on a } \\
\text { range of issues. Publish literature to keep clinicians apprised of latest issues and } \\
\text { best practice }\end{array}$ \\
\hline Indemnity providers & Represent the profession in dentolegal matters. Provide guidance to minimise risk \\
\hline
\end{tabular}

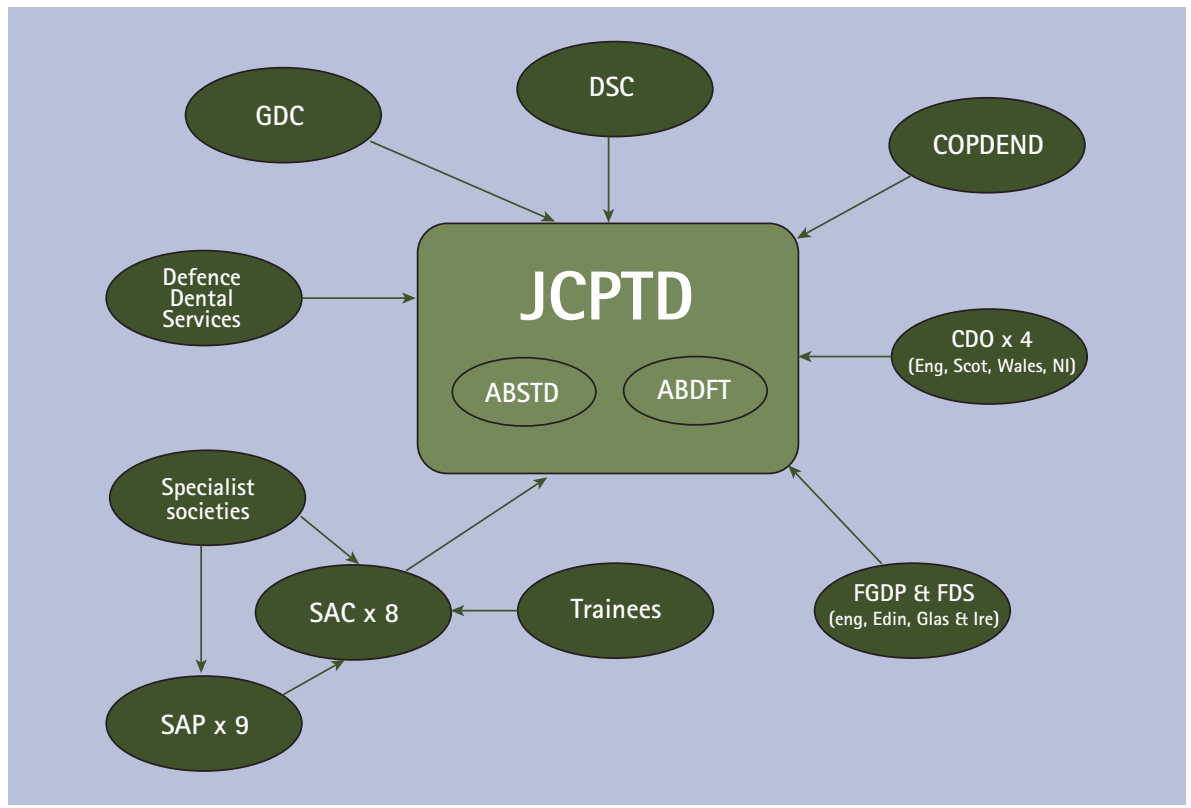

Fig. 3 Key stakeholders represented on the JCPTD

determine any gross uplift for GDPs and GMPs directly. ${ }^{40}$

There are dedicated societies for most of the dental specialties, and these serve to represent the views of their members, as well as to promote and advance their and societies for DCPs are in existence: the British Association of Dental Nurses, British Society of Dental Hygiene and Therapy, British Association of Dental Therapists, Dental Technologists Association, and Clinical Dental Technicians Association, to name a few.

\section{INDEMNITY PROVIDERS}

Until the late 19th century, doctors were personally liable for the payment of any compensation arising from negligence on their behalf. However, in 1885, a British doctor (David Bradley) was wrongly convicted after an epileptic patient had a seizure in his surgery and awoke believing she had been raped. Despite evidence to the contrary, Dr Bradley was sentenced and served eight months of a two year term before being pardoned. There was outrage in the medical community and many took the view that the conviction would have not resulted had expert evidence been submitted on Dr Bradley's behalf. ${ }^{41}$ As a result of this case, the Medical Defence Union was formed in 1885, and the Medical Protection Society shortly after in 1892 in order to provide the funds and guidance to defend cases against their members.

In modern times, having arrangements for professional indemnity cover is mandatory ${ }^{42}$ in order that patients can be fully compensated when appropriate. Specialist dental indemnity providers that have derived from their ancestral medical organisations are now in existence.

\section{CONCLUSION}

It is clear that dentistry in the United Kingdom - spanning primary and secondary care, public and private sectors, general and specialty divisions, and the four constituent countries - demands a wide range of supportive and regulatory bodies. Some of these bodies are centuries old, while others have been created in the last year. Either way, their roles are necessarily intertwined, occasionally overlapping, and periodically reshaped and transferred as defunct organizations are removed and new ones instated. Tables 3 and 4 provide an overview of key roles and acronyms.

While we have made every effort to ensure this paper remains contemporary, the fluid nature of the organisations covered invariably means that there may be some discrepancies by the time it reaches 
print. Nevertheless, we anticipate that this paper will represent a useful resource as the information contained herein is otherwise spread very thinly among a myriad of disparate sources. Where known, we have indicated the likely future role of the organisation in question. What is certain is that there will continue to be change.

For those with relatively few years' experience among these organisations, the system can appear daunting and opaque. It is worth investing the time to become acquainted with it, however, as understanding the system within which you practise is the first step to its improvement. We hope that this paper has gone some way towards that understanding and has empowered the reader to understand who does what in the business of dentistry.

The authors wish to acknowledge Amanda Little Policy Manager, General Dental Council; Anne Mochrie, Royal College of Surgeons of England; and Jan Morgan, Conciliation \&t Mediation Manager, London Deanery.

1. Department of Health. Equity and excellence: liberating the NHS. London: The Stationery Office, 2010, Cm 7881.

2. Ministry of Health and Department of Health for Scotland. A national health service. London: The Stationery Office, 1944

3. NHS Choices: About the NHS http://www.nhs.uk/ NHSEngland/thenhs/about/Pages/overview.aspx. Accessed 30 May 2010.

4. HM Government. Government response to the Health Select Committee on commissioning. London: The Stationery Office, 2010, Cm 7877.

5. HM Government. The National Institute for Clinical Excellence (Establishment and Constitution) Order 1999. London: The Stationery Office, 1999.

6. HM Government. The National Institute for Clinical Excellence (Establishment and Constitution) Amendment Order 2005. London: The Stationery Office, 2005.

7. Department of Health. Liberating the NHS: Report of the Arm's Length Bodies review. London: The Stationery Office, 2010.

8. HM Government. National Health Service Act 1977: directions to Health Authorities, Primary Care Trusts and NHS Trusts in England. London: The Stationery Office, 2001.

9. Mellows-Facer A (ed). Key issues for the new Parliament 2010. London: House of Commons Library Research, 2010. p 57.

10. Department of Health. Reconfiguring the Department of Health's Arm's Length Bodies. London: DH Publications, 2004.

11. HM Government. Health and Social Care Act 2008 Chapter 14. London: The Stationery Office, 2008.

12. HM Government. The Dentists Act 1984 (Amendment) Order 2005. London: The Stationery Office, 2005.

13. The Shipman Inquiry. Safeguarding patients: lessons from the past - proposals for the future. London: The Stationery Office, 2004

14. HM Government. Trust, assurance and safetythe regulation of health professionals in the 21st century. London: The Stationery Office, 2007.

15. General Dental Council. Minutes of special Council meeting, 28 Mar 2007. London: General Dental Council, 2007. Paragraph 21

16. HM Government. General Dental Council (Constitution of Committees) Rules 2009. London: The Stationery Office, 2009.

17. Department of Health. General Dental Council (Constitution) Order 2009. London: The Stationery Office, 2009

18. General Dental Council. The first five years. 3rd ed. London: General Dental Council, 2008.

19. General Dental Council. How we check the quality of education and training: a guide for course providers and awarding bodies. London: General Dental Council, 2009.

20. General Dental Council. Revalidation consultation opens (Oct 2010). Press release. London: General Dental Council, 2010

21. General Dental Council. General Dental Council (Distinctive Branches of Dentistry) Regulations 1998. London: General Dental Council, 1998.

22. General Dental Council. Consultation paper on introduction of specialist titles and specialist lists. London: General Dental Council, 1991.

23. NHS Executive. Report of the Chief Dental Officer on UK specialist dental training. London: The Stationery Office, 1995.

24. Department of Health. Hospital doctors: training for the future. Report of the working group on specialist medical training. London: The Stationery Office, 1993.

25. General Dental Council. The accord between the General Dental Council and the dental faculties of the Royal Surgical Colleges and other educational bodies. London: General Dental Council, 1996.

26. General Dental Council. Interim memorandum of understanding between the General Dental Council $(G D C)$ and the members of the Joint Committee for Specialist Training in Dentistry (JCSTD). London:
General Dental Council, 2008.

27. Joint Committee for Specialist Training in Dentistry. Joint Committee for Postgraduate Training in Dentistry (JCPTD) terms of reference and standing orders. London: Joint Committee for Specialist Training in Dentistry, 2010.

28. General Dental Council. Protecting patients hrough the specialties. London: General Dental Council, 2010.

29. General Dental Council. GDC response Department of Health consultation on the framework for the registration of health and adult social care providers. London: General Dental Council, 2008.

30. Care Quality Commission, General Dental Council. Memorandum of understanding between the Care Quality Commission and the General Dental Council. London: Care Quality Commission, Sep 2010.

31. Adapted from: General Medical Council. Quality framework for specialty including GP training. London: General Medical Council, 2010.

32. UK Committee of Postgraduate Dental Deans and Directors. A reference guide for postgraduate denta specialty training in the UK: The Dental Gold Guide. UK Committee of Postgraduate Dental Deans and Directors, 2009.

33. Faculty of General Dental Practice. About us. http:// www.fgdp.org.uk/patient_info/about_us_html. Accessed 24 March 2010.

34. General Dental Council. Specialist Lists Review Group final report: General Dental Council meeting 07 Dec 2005. London: General Dental Council, 2005

35. Faculty of General Dental Practice (UK) and Faculty of Dental Surgery. New MJDFexam website goes live. Press release. London: Faculty of General Denta Practice (UK) and Faculty of Dental Surgery, 2007.

36. Joint Committee for Specialist Training in Dentistry A manual of specialist training in dentistry in the United Kingdom and Ireland. London: Faculty of Dental Surgery, 1999.

37. The Royal College of Surgeons of Edinburgh The Royal Odonto-Chirurgical Society of Scotland. http://www.rcsed.ac.uk/site/748/default.aspx. Accessed on 30 May 2010

38. Joint Committee for Postgraduate Training in Dentistry. Terms of reference and standing orders. London: Joint Committee for Postgraduate Training in Dentistry, 2010.

39. British Dental Association. About the BDA overview. http://www.bda.org/about-the-bda/ overview.aspx. Accessed 24 March 2010.

40. BDA: Government intentions not helpful. Br Dent J 2010; 209: 331.

41. Cross R. Medico-Parliamentary. Br Med J 1885; 2: 181-182.

42. General Dental Council. Indemnity fact sheet. London: General Dental Council, January 2010. 